lệ tràn dịch khớp giảm $(5,6 \%)$ so với ban đầu $(32,2 \%)$.

Mức độ đau và chức năng vận động khớp gối được cải thiện: điểm VAS trung bình giảm từ $6,72 \pm 1,50$ (T0) xuống 2,63 $\pm 1,15$ (T3) và 1,53 $\pm 1,30$ điểm (T6), $p<0,05$. Điểm WOMAC đau, WOMAC cứng khớp, WOMAC vận động và WOMAC chung đều có sự cải thiện, điểm WOMAC chung giảm từ $37,20 \pm 7,68$ xuống $20,57 \pm 5,71$ (T3) và $13,03 \pm 5,52$ (T6). Sự khác biệt có ý nghĩa thống kê với $p<0,05$.

\section{TÀI LIÊU THAM KHẢO}

1. Nguyễn Văn Đàn, Nguyễn Thị Nguyên Sinh, Búi Chí Bảo, et al. (2018), "Bước đâu đánh giá hiệu quả điêuu trị thoái hóa khớp gối của bài thuốc nam sưu tầm trền địa bàn tỉnh Sóc Trăng", Tạp chí Y hoc Thành phố Hồ Ċí Minh, 22 (3), pp. 424-430.

2. Phạm Hoài Thu, Nguyễn Thị Thoa, Trân Thu Giang, et al. (2020), "Kết quá điều trị thoái hóa khớp gối nguyên phát bằng liệu pháp huyết tương giàu tiểu cầu sau 6 tháng", Tạp chí Nghiên cứu Y học, 134 (10), pp. 65-7.

3. Iraj Abari (2016), "2016 ACR Revised Criteria for Early Diagnosis of Knee Osteoarthritis", Therapeutic Advances in Neurological Disorders, 3 pp. 118.

4. Hassan A.S, EI-Shafey A. M., and Ahmed H. S. (2015), "Effectiveness of the intra-articular injection of platelet rich plasma in the treatment of patients with primary knee osteoarthritis", The Egyptian Rheumatologist, 37 pp. 119-124.

5. Ziad $M$ Hawamdeh and Jihad M. Al-Ajlouni (2013), "The clinical pattern of knee osteoarthritis in Jordan: a hospital based study", International journal of medical sciences, 10 (6), pp. 790-795.

6. Clémence Palazzo, Christelle Nguyen, MarieMartine Lefevre-Colau, et al. (2016), "Risk factors and burden of osteoarthritis", Annals of Physical and Rehabilitation Medicine, 59 (3), pp. 134-138.

7. Ferhat Say, Deniz Gürler, K. Yener, et al. (2013), "Platelet-Rich Plasma Injection Is More Effective than Hyaluronic Acid in the Treatment of Knee Osteoarthritis", Acta chirurgiae orthopaedicae et traumatologiae Cechoslovaca, 80 pp. 278-283.

\title{
THẨM ĐİNH PHƯƠNG PHÁP ĐİNH LƯợNG ROTUNDIN SULFAT TRONG THUỐC TIÊM ROTUNDIN SULFAT BẰNG SẮC KÝ LỎNG HIỆU NĂNG CAO
}

\section{TÓM TẮT}

Mục tiêu: Thẩm định phương pháp định lương rotundin sulfat trong thuốc tiêm rotundin sulfat bắng sắc ký lỏng hiệu năng cao (HPLC) nhằm góp phần tiêu chuẩn hóa chẩt lượng sản phẩm. Phương pháp: Tiến hành đinh lượng Rotundin sulfat bằng phương pháp HPLC với cột sắc ký C18 $(4,6 \times 150$ mm, $5 \mu \mathrm{m})$, tốc độ dòng $1,0 \mathrm{~mL} /$ phút, detector PDA tại bước sóng $281 \mathrm{~nm}$, thể tích tiêm mẫu: $15 \mu \mathrm{L}$, dung môi pha động gồm acetonitril và nước (70:30). Kết quả: Phướng pháp đảm bảo tính thích hợp, tính đặc hiệu, khoảng tuyến tính, độ lặp lại, độ đúng và giới hạn phát hiện theo qui định của IC̉H. Kết luận: Phương pháp định lượng đảm bảo các yêu cầu và có thể sử dụng để định lượng rotundin sulfat trong thuốc tiêm rotundin sulfat.

Tư khóa: Rotundin sulfat, thuốc tiêm, ICH.

\section{SUMMARY \\ VALIDATION QUALITY METHOD FOR ROTUNDINE SULFATE IN ROTUNDINE SULFATE INJECTION BY HIGH PERFOMANCE LIQUID CHROMATOGRAPHY \\ Objective: To validate the assay method for the}

*Học viện Quân y

Chịu trách nhiệm chính: Nguyễn Văn Bạch

Email: bachhvqy@gmail.com

Ngày nhận bài: 30/8/2021

Ngày phản biện khoa học: 27/9/2021

Ngày duyệt bài: 19/10/2021

\section{Nguyễn Văn Bạch ${ }^{1}$, Nguyễn Văn Minh ${ }^{1}$}

quantification of rotundine sulfate in rotundine sulfate injection by high performance liquid chromatography (HPLC) in order to contribute to standardization of product quality. Methods: Quantification of Rotundine sulfate was carried out by HPLC method with chromatographic column C18 $(4.6 \times 150 \mathrm{~mm}, 5 \mu \mathrm{m})$, flow rate $1.0 \mathrm{~mL} / \mathrm{min}, \mathrm{PDA}$ detector at $281 \mathrm{~nm}$, sample injection volum: $15 \mu \mathrm{L}$, mobile phase solvent: acetonitrile: water (70:30). Results: The method ensured suitability, specificity, linearity, repeatability, precision, and limits of detection as specified by ICH. Conclusion: The quantitative method responded the requirements and can be used to quantify rotundine sulfate in injection.

Keywords: Rotundine sulfate, injection, ICH

\section{I. ĐẶT VẤN ĐỀ}

Rotundin sulfat (RS) là một muối alcaloid, hoạt chất chính của củ bình vôi, có tác dụng an thần gây ngủ chống co giật, loại nguyên liệu có sẵn ở Việt Nam [1]. Hiện nay có nhiêu dạng chế phẩm chứa RS sản xuất tại Việt Nam, đặc biệt dạng thuốc tiêm thường không ổn định và bị giảm hàm lượng hoạt chất nhanh trong thời gian bảo quản. Nguyên nhân do RS là một chất dế bị oxy hóa đặc biệt là khi pha thành dung dịch bởi các yếu tố như oxy, ánh sáng, nhiệt độ... có ảnh hưởng đến tốc độ oxy hóa phân hủy thuốc [2]. Hiện nay, có một số tác giả nước ngoài đã nghiên cứu về phương pháp định lượng Rotundin 
trong thuốc tiêm RS bằng phương pháp HPLC [3], [4]. Vì vậy, nghiên cứu này được thực hiện nhằm góp phần cung cấp các dữ liệu về phương pháp định lượng RS trong thuốc tiềm RS và áp dụng để đánh giá chất lượng một số chế phẩm đang lưu hành.

\section{II. ĐỐI TƯƠ'NG VÀ PHƯƠNG PHÁP NGHIÊN CỨU \\ 2.1. Nguyên vật liệu \\ *Nguyên vật liệu}

- Rotundin sulfat chuẩn: Đạt chuẩn phòng thí nghiệm.

- Methanol, Acetonitril, nước cất: Đạt tiêu chuẩn P.A (Merck Đức).

2.2. Thiết bị nghiên cứu

- Máy sắc ký lỏng hiệu năng cao (HPLC): Water e2695, Detector 2998 PDA, cột SunFireTM $(4,6 \mathrm{~mm} \times 25 \mathrm{~cm} ; 5 \mu \mathrm{m})(\mathrm{Mỹ})$.

- Cân phân tích Mettler toledo có độ chính xác 0,1mg (Thụy Sỹ).

- Màng lọc nilon Sartorius Minisart kích thước màng $0,45 \mu \mathrm{m}$ (Đức).

- Hệ thống phễu thuỷ tinh Sartotius (Đức).

- Các dụng cụ khác đạt tiêu chuẩn phân tích.

\subsection{Phương pháp nghiên cứu}

\section{*Xứ lý mấu}

- Dung dịch chuẩn: Cân chính xác 0,030g RS chuẩn cho vào bình định mức $100 \mathrm{~mL}$, thêm $\mathrm{MeOH}$ đến định mức, lắc đều. Pha loãng $10,0 \mathrm{~mL}$ dung dịch thu được thành $100,0 \mathrm{ml}$ bằng $\mathrm{MeOH}$ được dung dịch có nồng độ $30 \mu \mathrm{g} / \mathrm{ml}$

- Dung dich thử: Hút chính xác $1,0 \mathrm{~mL}$ chế phẩm (tương đương với $0,03 \mathrm{~g}$ RS) vào bình định mức $100,0 \mathrm{~mL}$, thêm $\mathrm{MeOH}$ đến định mức, lắc đều và lọc. Pha loãng $10,0 \mathrm{~mL}$ dung dịch thu được thành $100,0 \mathrm{ml}$ bằng $\mathrm{MeOH}$.

* Điều kiện sắc ký

- Cột C18 (250mm x 4,6mm) được nhồi pha tĩnh $(5 \mu \mathrm{m})$.

- Tốc độ dòng: 1,0 mL/phút.

- Dertector PDA tai bước sóng $281 \mathrm{~nm}$.

- Thể tích tiêm mẫu: $15 \mu \mathrm{L}$

- Dung môi pha động: Acetonitril : nước (70:30)

*Thẩm định phương pháp theo hướng dẫn của ICH đánh giá các tiêu chí sau:

- Tính tương thích hệ thống:

Tiến hành tiêm 06 lần mẫu chuẩn có nồng đô khoảng $30 \mu \mathrm{g} / \mathrm{mL}$ vào hệ thống HPLC, tiến hành sắc ký theo diều kiện đã chọn. Ghi lại kết quả: thời gian lưu, diện tích pic, hệ số bất đối, số đĩa lý thuyết và tính toán giá trị RSD (\%).

- Tính chọn lọc - đặc hiệu:

Tiến hành sắc ký theo điều kiện đã xác định: mẫu chuẩn có nồng độ $30 \mu \mathrm{g} / \mathrm{mL}$, mẫu thử và mẫu trắng (không chứa dược chất). Ghi lại các sắc ký đồ và đáp ứng pic tại các vị trí tương ứng với thời gian lưu của hoạt chất.

Yêu cầu: pic của RS trong sắc ký đồ (SKĐ) mẫu chuẩn phải cân đối, sắc nét, trong SKĐ mẫu thử phải đảm bảo được nhận diện rõ ràng, tách hoàn toàn khỏi các pic tạp, đồng thời không xuất hiện trong SKĐ mẫu trắng.

- Đường chuẩn và khoảng tuyến tính:

Tiến hành sắc ký dãy chuẩn có nồng độ nằm trong khoảng 15,0 - 60,0 $\mathrm{gg} / \mathrm{mL}$ theo điều kiên đã xây dựng, ghi lại đáp ứng pic của RS tại các nồng độ tương ứng, xây dựng phương trình hồi quy thể hiện sự tương quan giữa diên tích pic và nồng độ của $R S$, xác định hệ số tương quan $R^{2}$.

- Giới hạn phát hiện (LOD), Giới hạn định lượng (LOQ):

Tiến hành sắc ký 03 lần mẫu trắng. Ghi lại độ nhiễu đường nền tại thời gian lưu tương ứng với thời gian lưu của RS.

Giá trị LOD, LOQ được xác định theo công thức: $L O D=k \cdot S D / \delta$

Trong đó: SD là độ lệch chuẩn của đáp ứng của mẫu trắng, $\delta$ là độ dốc đường hồi quy tuyến tính; $\mathrm{k}=3,3$ cho LOD; $\mathrm{k}=10$ cho LOQ.

$$
\mathrm{LOD}=\frac{3,3 \times \mathbf{S D}}{\delta} \quad \mathrm{LOQ}=\frac{1 \mathrm{o} x S D}{\delta}
$$

- Độ lặp lại: Độ lặp lại của phương pháp được xác định bằng cách tiến hành 06 thí nghiệm riêng biệt để định lượng một mẫu thử 30,0 $\mu \mathrm{g} / \mathrm{mL}$. Chạy sắc ký và ghi lại sắc ký đồ của 06 mâu thử. Tính giá trị RSD (\%) của diện tích pic và thời gian lưu.

- Độ đúng: Độ đúng của phương pháp được thực hiện thao phương pháp thêm chuẩn: Pha mẩu chuẩn: Cân chính xác $0,050 \mathrm{~g}$ Rotundin chuẩn cho vào bình định mức $50,0 \mathrm{~mL}$, thêm $\mathrm{MeOH}$ đến định mức, lắc đều, thu được dung dịch RS có nồng độ $1000 \mu \mathrm{g} / \mathrm{mL}$ ).

\section{KẾT QUẢ NGHIÊN CỨU VÀ BÀN LUÂ̂N}

3.1. Kết quả đánh gái tính tương thích hệ thống. Để đánh giá tính tương thích hệ thống sắc ký, tiến hành tiêm 06 lần mẫu chuẩn có nồng độ khoảng $30,06 \mu \mathrm{g} / \mathrm{mL}$ vào hệ thống HPLC, sắc ký với điều kiện đã chọn, kết quả được trình bày ở bảng 1 và hình 1 .

Bảng 1. Kết quả tính tương thích hệ thống

\begin{tabular}{|c|c|c|c|c|}
\hline STT & $\begin{array}{c}\text { Thời } \\
\text { gian lưu }\end{array}$ & $\begin{array}{c}\text { Spic }_{\text {pic.s }} \\
(\mu \mathrm{A} . \mathrm{s}\end{array}$ & $\begin{array}{c}\text { Hệ số } \\
\text { bất đối } \\
\text { xứng }\end{array}$ & $\begin{array}{c}\text { Số đĩa } \\
\text { lý } \\
\text { thuvết }\end{array}$ \\
\hline 1 & 5,599 & 316242 & 1,20 & 12797 \\
\hline 2 & 5,606 & 314301 & 1,19 & 12998 \\
\hline 3 & 5,612 & 315374 & 1,20 & 12854 \\
\hline
\end{tabular}




\begin{tabular}{|c|c|c|c|c|}
\hline $\mathbf{4}$ & 5,615 & 315899 & 1,20 & 12893 \\
\hline $\mathbf{5}$ & 5,618 & 315285 & 1,20 & 12828 \\
\hline $\mathbf{6}$ & 5,620 & 316484 & 1,21 & 12739 \\
\hline $\mathbf{X}$ & 5,610 & 315597,5 & 1,20 & 12851,5 \\
\hline SD & 0,0079 & 790,02 & 0,0063 & 88,74 \\
\hline $\begin{array}{l}\text { RSD } \\
(\%)\end{array}$ & 0,14 & 0,25 & 0,53 & 0,69 \\
\hline
\end{tabular}

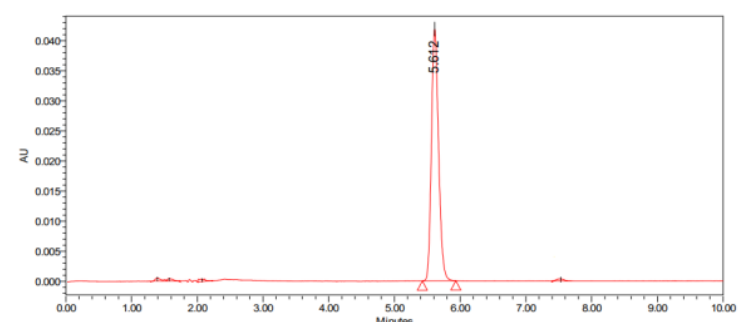

Hinh 1. Sắc ký đồ của mẫu chuẩn Rotundin sulfat

Từ kết quả bảng 1 và hình 1 cho thấy: Thời gian lưu của RS là $5,61 \pm 0,0079(\mathrm{RSD}=0,14 \%)$. Diện tích pic của RS tại nồng độ khảo sát là $315597,5 \pm 790,02$ (RSD=0,25\%). Hệ số bất đôi của pic RS là $1,20 \pm 0,0063(R S D=0,53 \%)$. Số đĩa lý thuyết của pic RS là $12851,50 \pm 88,73$ (RSD=0,69\%). Như vậy, độ lệch chuẩn tương đối (RSD) về thời gian lưu, diện tích pic, hệ số bất đối $\left(A_{s}<2\right)$, số đĩa lý thuyết của RS đều đạt yêu cầu $(R S D<2 \%)$, điều này khẳng định các điều kiện sắc ký đã lựa chọn và hệ thống HPLC sử dụng phù hợp và đảm bảo ổn định cho định lượng RS.

3.2. Kết quả đánh giá độ đặc hiệu. Để đánh giá độ đặc hiệu, tiến hành sắc ký kiên tiếp mẫu chuẩn, mẫu thử và mẫu trắng trong cùng điều kiện sắc ký đã lựa chọn. Kết quả được trình bày ở hình 2 .

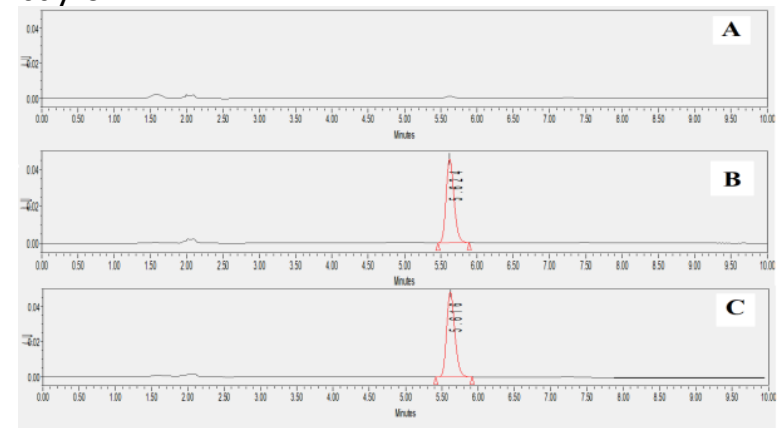

Hình 2. Kêt quả sắc ký đồ mẫu trăng (A), mẫu chuẩn (B) và mẫu thử (C) khi khảo sát độ đặc hiệu

Từ kết quả hình 2 cho thấy: Tại vị trí xuất hiện đáp ứng pic của RS trên sắc ký đồ mẫu chuẩn, xuất hiện pic tương ứng trên sắc ký đồ mẫu thử và đồng thời không xuất hiện pic tương ứng trên mẫu trắng. Pic của RS trên mẫu thử là cân đối, sắc nét, tách hoàn toàn khỏi pic tạp. Do đó, phương pháp và điều kiện sắc ký đã lựa chọn đảm bảo độ chọn lọc và tính đặc hiệu khi phân tích RS.

\subsection{Kết quả khảo sát độ tuyến tính và} xây dựng đường chuẩn. Tiến hành sắc ký dãy chuẩn RS có khoảng nồng độ từ 15,0-60,0 $\mu \mathrm{g} / \mathrm{mL}$ theo điều kiện đã lựa chọn. Kết quả diện tích pic và nồng độ của dung dịch chuẩn RS được trình bày trong bảng 2 và hình 3 .

Bảng 2. Diện tích pic và nông độ của dung dịch chuần Rotundin sulfat

\begin{tabular}{|c|c|c|}
\hline $\begin{array}{c}\text { Nồng độ } \\
\text { (pg/mL) }\end{array}$ & $\begin{array}{c}\text { Thời gian lưu } \\
\text { (phút) }\end{array}$ & $\begin{array}{c}\text { Spic } \\
\text { (pAU.s) }\end{array}$ \\
\hline 15,03 & 5,623 & 159742 \\
\hline 20,04 & 5,626 & 221411,33 \\
\hline 30,06 & 5,618 & 315889,33 \\
\hline 40,08 & 5,619 & 415911 \\
\hline 50,10 & 5,625 & 519532,67 \\
\hline 60,12 & 5,637 & 608561,67 \\
\hline
\end{tabular}

Đường chuấn: $y=9946,5 x+16994 ; R^{2}=0,9992$

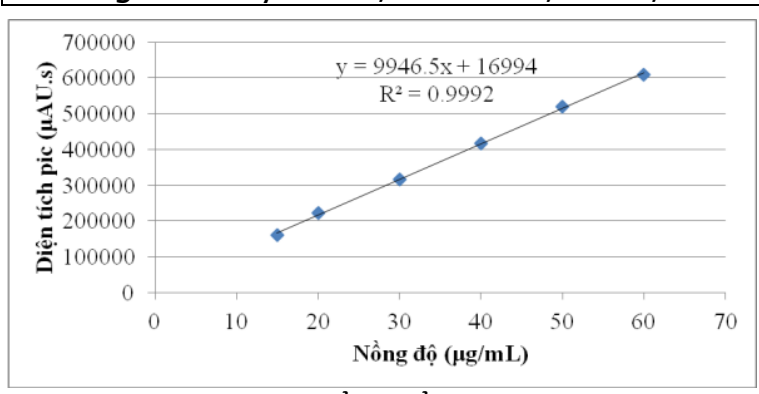

Hình 3. Đường chuẩn thể hiện môi tương quan tuyến tính giữa diện tích pic và nồng độ Rotundin sulfat

Từ kết quả bảng 2 và hình 3 cho thấy: Trong khoảng nồng độ khảo sát có mối tương quan tuyến tính giữa diện tích pic và nồng độ $R S$. Đường tương quan thu được là đường thẳng có hệ số $R^{2}$ là $0,9992\left(R^{2}>0,99\right)$. Do đó, có thể sử dụng phương pháp HPLC để định lượng RS trong các mẫu phân tích.

3.4. Kết quả đánh giá độ lặp lại. Độ lặp lại của phương pháp được xác định bằng cách tiến hành sắc ký theo điều kiện đã lựa chọn 06 thí nghiệm riêng biệt để định lượng một mẫu thử $30,0 \mu \mathrm{g} / \mathrm{mL}$. Nồng độ RS trong các mẫu được tính toán dựa vào đường chuẩn. Kết quả được trình bày trong bảng 3 .

Bảng 3. Kêt quả đánh giá độ lặp lại

\begin{tabular}{|c|c|c|c|}
\hline STT & $\begin{array}{l}\text { Thời gian } \\
\text { lưu (phút) }\end{array}$ & $\begin{array}{c}S_{\text {pic }} \\
(\mu \mathrm{AU} . \mathrm{s})\end{array}$ & $\begin{array}{l}\text { Nồng độ } \\
(\mu \mathrm{g} / \mathrm{mL})\end{array}$ \\
\hline 1 & 5,422 & 320573 & 30,38 \\
\hline 2 & 5,446 & 321964 & 30,52 \\
\hline 3 & 5,421 & 320103 & 30,33 \\
\hline
\end{tabular}




\begin{tabular}{|c|c|c|c|}
\hline 4 & 5,426 & 320708 & 30,39 \\
\hline 5 & 5,421 & 320208 & 30,35 \\
\hline 6 & 5,382 & 320685 & 30,39 \\
\hline$\overline{\mathbf{X}}_{ \pm \mathrm{SD}}$ & $5,4197 \pm$ & 320707 & $30,39 \pm$ \\
& 0,0021 & $\pm 665,18$ & 0,06 \\
\hline $\mathrm{RSD}(\%)$ & 0,38 & 0,21 & 0,22 \\
\hline
\end{tabular}

Từ kết quả bảng 3 cho thấy: Độ lệch chuẩn tương đối RSD khảo sát thấp (RSD=0,22\%). Như vậy, phương pháp phân tích có độ chính xác cao, đảm bảo yêu cầu (RSD<2\%) để định lượng RS trong mẫu phân tích.

3.5. Kết quả đánh giá độ đúng. Tiến hành sắc ký theo chương trình đã lựa chọn thu được kết quả như bảng 4. Dựa vào hàm lượng RS đã biết của dung dịch chuẩn và dung dịch thử thính được lượng RS chuẩn tìm thấy trong mẫu thử thêm chuẩn.

Bảng 4. Kêt quả khảo sát độ đúng

\begin{tabular}{|c|c|c|c|c|c|}
\hline STT & $\begin{array}{l}\text { Lương chuấn } \\
\text { thêem vào } \\
\text { (mg) }\end{array}$ & $\begin{array}{l}\text { Spic Của } \\
\text { mấu thử } \\
\text { ( } \mu \text { AU.s) }\end{array}$ & $\begin{array}{c}\text { Spic của mầu } \\
\text { thử + chuẩn } \\
\text { ( } \mu \text { AU.s })\end{array}$ & $\begin{array}{c}\text { Nồng độ } \\
\text { mấu thử + chuẩn } \\
(\mu \mathrm{g} / \mathrm{mL})\end{array}$ & $\begin{array}{c}\text { Độ thu hôi } \\
(\%)\end{array}$ \\
\hline \multirow{3}{*}{1} & 12,3 & 169341 & 287208 & 27,00 & 99,31 \\
\hline & 12,3 & 170780 & 287306 & 27,01 & 98,18 \\
\hline & 12,3 & 169616 & 285587 & 26,84 & 97,71 \\
\hline \multirow{3}{*}{2} & 15,1 & 169876 & 314311 & 29,75 & 97,36 \\
\hline & 15,1 & 169639 & 314304 & 29,75 & 97,51 \\
\hline & 15,1 & 169343 & 315390 & 29,86 & 98,44 \\
\hline \multirow{3}{*}{3} & 18,2 & 170393 & 345885 & 32,95 & 98,58 \\
\hline & 18,2 & 169785 & 346845 & 33,045 & 99,46 \\
\hline & 18,2 & 170393 & 346952 & 33,056 & 99,18 \\
\hline
\end{tabular}

Từ kết quả bảng 4 ta thấy: Lượng chất chuấn thu hồi lại được nằm trong khoảng cho phép (97$103 \%) ; R S D=0,803 \%$ (RSD < 2\%) chứng tỏ phương pháp sử dụng có độ đúng cao.

3.6. Kết quả xác định giới hạn phát hiện (LOD) và giới hạn định lượng (LOQ). Để xác định giới hạn phát hiện và giới hạn định lượng, tiến hành tiêm sắc ký 03 lần mẫu trắng, ghi lại độ nhiễu đường nền tại thời gian lưu tương ứng với thời gian lưu của RS, thể hiện ở bảng 5 .

Bảng 5. Kêt quả khảo sát $\angle O D, \angle O Q$

\begin{tabular}{|c|c|}
\hline Mẫu & $\begin{array}{c}\text { Độ nhiếu đường nền tại thời gian } \\
\text { lưu cưa RS }\end{array}$ \\
\hline $\mathbf{1}$ & 11314 \\
\hline $\mathbf{2}$ & 11439 \\
\hline $\mathbf{3}$ & 11510 \\
\hline $\mathbf{X}$ & 11421 \\
\hline SD & 99,23 \\
\hline
\end{tabular}

Từ số liệu bảng 5, nhận thấy: Âp dụng công thức tính kết quả cho giới hạn phát hiện (LOD) và giời hạn định lượng (LOQ) của RS lần lượt là $0,03 \mu \mathrm{g} / \mathrm{mL}$ và $0,09 \mu \mathrm{g} / \mathrm{mL}$.

Như vậy, phương pháp định lượng Rotundin sulfat đã được thẩm định đầy đủ theo hướng dẫn của ICH với các chỉ tiêu: Tính tương thích của hệ thống, độ đặc hiệu chọn lọc, khoảng nồng độ tuyến tính, giới hạn phát hiện, giới hạn định lượng dưới, độ đúng và độ chính xác. Phương pháp định lượng có khoảng nồng độ tuyến tính trong khoảng $15,0-60,0 \mu \mathrm{g} / \mathrm{mL}$, đảm bảo phân tích được các mấu với các nồng độ chất phân tích khác nhau.

\section{KẾT LUÂ̂N}

- Đã lựa chọn điều kiện định lượng bằng sắc ký lỏng hiệu năng cao như sau: cột C18 (250mm

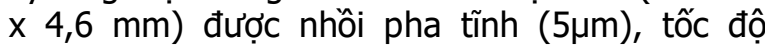
dòng: 1,0mL/phút, detector PDA tại bước sóng $281 \mathrm{~nm}$, thể tích tiêm mẫu: $15 \mu \mathrm{L}$, dung môi pha động: Acetonitril: nước (70:30). Đã xây dựng được đường chuẩn của RS có khoảng nồng độ từ $15,0-60,0 \mu \mathrm{g} / \mathrm{mL}$ theo điều kiện đã lựa chọn.

- Phương pháp cũng được thẩm định đầy đủ các chỉ tiêu theo hướng dẩn của ICH về thẩm định phương pháp phân tích.

\section{TÀI LIỆU THAM KHẢO}

1. Viện dược liệu (2004), Cây thuốc và động vật làm thuốc ở Viête Nam, tập I, Nhà xuất bản khoa hoc kỹ thuât, Hà̀ Nôi, tr. 210-250.

2. Li L., Zhan X., Li K., Yang X. (2001), Influence of light and heat on the stability of rotundine sulfate injection, Journal of Pharmaceutical Sciences, 90 (10), pp. 1497-1504.

3. Feng M., Zhu Y., Wen J. (2008), HPLC determination of the related substances Rotundine and Rotundine Sulfate Injection, Chinese Journal of Pharmaceutical Analysis, 7, pp.1180-1183.

4. Yin F., Wang $X .$, Li J. (2010), "Determination of Rotundin Sulfae Injection and Related Compounds by HPLC", Chinese Journal of Pharmaceutical Affairs, 2, pp. 161-163.

5. International Conference on Harmonisation (2005), ICH Q2 (R1) Validation of analytical procedures: Text and methodology. 